\title{
GMR
}

\section{Prediction efficiency of PITX2 DNA methylation for prostate cancer survival}

\author{
Z.M. Luan ${ }^{1}$, H. Zhang ${ }^{1}$ and X.L. Qu ${ }^{2}$ \\ ${ }^{1}$ Department of Urology, Affiliated Hospital of WeiFang Medical College, \\ WeiFang, China \\ ${ }^{2}$ Department of Urology, LaiZhou City Peoples Hospital, LaiZhou, China \\ Corresponding author: X.L. Qu \\ E-mail: XiaoLuwf@126.com
}

Genet. Mol. Res. 15 (2): gmr.15026750

Received June 12, 2015

Accepted December 2, 2015

Published April 25, 2016

DOI http://dx.doi.org/10.4238/gmr.15026750

\begin{abstract}
This study determined the level of PITX2 methylation in prostate cancer and benign tissues and its relationship with the postoperative survival rate. Forty-four patients with prostate cancer who underwent radical prostatectomy and 43 patients with benign prostatic hyperplasia were selected. DNA was extracted from the tissues and PITX2 methylation status was quantitatively analyzed by using the EpiTect MethyLight method. The median follow-up time of the patients was 63 months and was used to analyze the relationship between PITX2 methylation status with tumor stage and survival rates. Median PITX2 gene expression in benign tissues was 1.46 , which was higher than that of tumor tissues with a median of $0.01(\mathrm{P}<0.001)$. The median methylation in the controls was less than $0.001 \%$, while the median methylation in the test group was $23.3 \%(\mathrm{P}=0.000)$. The number of patients with low methylation level in $\mathrm{T} 2$ stage was 15 , which was more than that in T3 and T4 stages (8 patients); while the number of patients with high methylation levels in T2 stage was 6 , which was less than that in T3 and T4 stages (15 patients) $(\mathrm{P}=0.035)$. The PITX2 gene expression level in prostate cancer tissues was lower than that in benign
\end{abstract}


tissues. A higher degree of PITX2 DNA methylation was associated with higher tumor stage and lower survival rates. PITX2 DNA methylation presents a good predictive value for prostate cancer survival.

Key words: DNA methylation; Prostate cancer; PITX2; Survival

\section{INTRODUCTION}

Prostate cancer is a common malignant tumor in the male urogenital system with increasing incidence (Daniũnaite et al., 2011; Tang et al., 2013). Radical prostatectomy and radiation therapy are the first choice for treatment, while the prognosis is different according to the clinical stage, pathological grading, and individual differences. PSA, a specific prostate marker, has been widely used in clinical laboratory tests for the diagnosis of prostate cancer. However, PSA detection presents a high false-positive rate and fails to accurately assess the malignancy grade of the tumor. Thus, it does not fully satisfy the clinician's need to determine the treatment modality for patients with prostate cancer (Goessl et al., 2001). Novel specific molecular markers for prostate cancer diagnosis and treatment are needed. DNA methylation changes in the early process of prostate cancer with high detection sensitivity and diversity test methods and is an ideal biomarker (Hoque et al., 2004; Bickers and Aukim-Hastie, 2009). As the most characterized type of epigenetic modification in prostate cancer, DNA methylation has become a hotspot in prostate cancer epigenetic studies and provides a new method for prostate cancer early diagnosis, prognosis assessment, and drug treatment. Many genes, closely related to the occurrence, development, and metastasis of prostate cancer, are methylated. Different tumors present specific methylated genes that could be chosen as biomarkers for the diagnosis and prognosis evaluation. Paired-like homeodomain transcription factor 2 (PITX2) is a downstream transcription factor of the classic Wnt signaling pathway and its mutation can cause a variety of diseases (Tian et al., 2012). This study explored PITX2 methylation in prostate cancer and benign tissues and its relationship with postoperative survival rate through assessing PITX2 expression and methylation levels in tissues from patients with prostate cancer.

\section{MATERIAL AND METHODS}

\section{General information}

Forty-four patients with prostate cancer who underwent radical prostatectomy and 43 patients with benign prostate hyperplasia were selected between May 2004 and November 2007. The mean ages in the two groups were $57.48 \pm 4.71$ and $56.81 \pm 3.52$ years old, respectively. The patient's age, weight, and other general clinical data showed no statistical difference ( $\mathrm{P}$ $>0.05$ ). The inclusion criteria were as follows: 1) patients received radical prostatectomy; 2) prostate cancer and benign hyperplasia were confirmed by pathology; 3) patients with no other malignant tumors that affect the test result.

Patients were staged according to the tumor staging standards promulgated by the International Union Against Cancer (Hermanek, 1992). T1 stage is clinical recessive tumor; T2 stage is confined to the prostate; T3 stage invades out of the prostate capsule; T4 stage is fixed tumor or invaded the adjacent tissues outside of the seminal vesicles. Twenty-one 
patients presented T2 stage and 23 patients were in stages T3 and T4. Twenty-four patients exhibited a Gleason score of 7, 14 patients presented Gleason scores of less than 7, and 6 patients presented Gleason scores higher than 7 . No bone metastasis was found prior surgery in all patients.

Patients with prostate cancer were postoperatively followed up for 36 to 70 months with a median follow-up time of 63 months. This study was approved by the hospital Ethics Committee and the patient or dependents signed the informed consent.

\section{DNA extraction}

Prostate tissue was homogenized with cracking liquid and combined with an equal volume of chloroform, mixed, and centrifuged at $2500 \mathrm{rpm}$ for $10 \mathrm{~min}$. The upper water phase was mixed with an equal volume of isopropyl alcohol and centrifuged at $2500 \mathrm{rpm}$ for 10 min. $\mathrm{NaCl}(5 \mathrm{M})$ was added to the water phase to a final concentration of $0.3 \mathrm{M}$. Another 2.5 time volume of ice anhydrous ethanol was added to collect the white precipitate. The white precipitate was diluted by $1 \mathrm{~mL}$ TE. The DNA concentration was calculated as follows: $(\mu \mathrm{g} /$ $\mathrm{mL})=\mathrm{A}_{260 \mathrm{~nm}} \times 50 \times 1 /$ optical path $\mathrm{x}$ dilution ratio. The DNA was then further purified by agarose gel electrophoresis.

\section{Real-time PCR}

SuperScript II transcription enzyme was used for reverse transcription and the realtime PCR was performed by using commercially specific primers and the corresponding mRNA TaqMan probe on ABI 7900 (Table 1). The TaqMan probes and PCR primers allowed us to distinguish methylated and unmethylated DNA. The DNA fragments were first treated with bisulfite and used for real-time PCR. cDNA dilution series was used to standardize each test and the experimental deviation of each sample was lower than $10 \%$. The $T B P$ gene was used as the reference.

\section{Table 1. Primer sequences.}

\begin{tabular}{l|l}
\hline Gene & Primer $\left(5^{\prime} \rightarrow 3^{\prime}\right)$ \\
\hline PITX2 & ataagcttgccaccatggagaccaactgccgcaaactgg \\
\hline GFP-SF1 & ccatcttcttcaaggacgacgac \\
\hline
\end{tabular}

\section{Methylation analysis}

After treatment with sodium bisulfite, DNA was amplified with EZ DNA methylation kit. The EpiTect MethyLight quantitative method was used to analyze PITX2 gene methylation level. A probe was designed complementary to the loci to be detected with a fluorescent dye on its 5 '-end and a quenching fluorescence probe on its 3'-end for real-time PCR.

\section{Statistical analysis}

All statistical analyses were performed using the SPSS11.5 software (Chicago, IL, USA). Measurement data are reported as means \pm standard deviation and enumeration data 
are reported as a percentage. Differences between groups were analyzed using the chi-square test, with $\mathrm{P}<0.05$ considered statistically significant.

\section{RESULTS}

\section{PITX2 expression in prostate cancer}

Real-time PCR results showed that the median value for PITX2 gene expression was 1.46 in benign tissues and 0.01 in carcinoma tissues. PITX2 expression in prostate cancer tissues was obviously lower than that in benign tissues $(\mathrm{P}<0.001)$. PITX2 expression and Gleason score did not significantly correlate with the tumor stage.

\section{PITX2 methylation level in prostate cancer and benign tissues}

PITX2 methylation level was detected in the two groups. PITX2 gene expression was significantly related to DNA methylation in the 44 tumor specimens. As shown in Figure 1, the median value of the methylation level in tumor (23.3\%) was markedly higher than that in benign tissues $(<0.001 \%$; $\mathrm{P}=0.000)$.

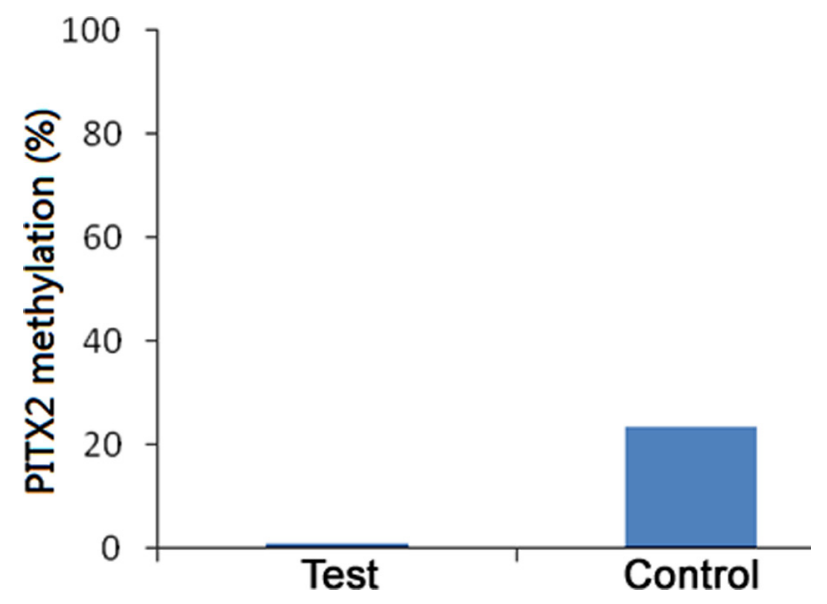

Figure 1. PITX2 methylation percentage in test and control groups $(\mathrm{P}=0.000)$.

\section{Association of PITX2 methylation with tumor staging}

The median value of PITX2 DNA methylation in prostate cancer was $23.3 \%$. We divided the patients with a methylation degree lower than the median value $(23.3 \%)$ as the low methylation subgroup and the patients with a methylation degree higher than the median value as the high methylation subgroup. The number of patients with low methylation in T2 stage was higher than that in $\mathrm{T} 3$ and $\mathrm{T} 4$ stages, while the number of patients with high methylation in $\mathrm{T} 2$ stage was less than that in $\mathrm{T} 3$ and $\mathrm{T} 4$ stages $(\mathrm{P}=0.035$; Table 2$)$. No significant correlation between tumor stage and PITX2 expression and Gleason score was observed. 
Table 2. Association of PITX2 methylation with tumor staging.

\begin{tabular}{l|c|c}
\hline PITX2 methylation level & Low methylation subgroup ( $\mathrm{N}=23)$ & High methylation subgroup ( $\mathrm{N}=21)$ \\
\hline T2 stage & $15(65 \%)$ & $6(29 \%)$ \\
\hline T3 and T4 stages & $8(35 \%)$ & $15(71 \%)$ \\
\hline$\chi^{2}$ & & \\
\hline $\mathrm{P}$ & & 5.909 \\
\hline
\end{tabular}

\section{Association of PITX2 methylation with survival rate}

In the subgroup of patients with low methylation, a higher number of patients exhibited a survival rate longer than 5 years, while, in the subgroup of patients with high methylation, a higher number of patients showed a survival rate shorter than 5 years $(P=0.034$; Table 3$)$.

Table 3. Association of PITX2 methylation with survival rate.
\begin{tabular}{l|c|c}
\hline PITX2 methylation level & Low methylation subgroup $(\mathrm{N}=23)$ & High methylation subgroup $(\mathrm{N}=21)$ \\
\hline Cases with survival $>5$ years & $18(78 \%)$ & $10(48 \%)$ \\
\hline Cases with survival $<5$ years & $5(22 \%)$ & $11(52 \%)$ \\
\hline$\chi^{2}$ & & 4.454 \\
\hline $\mathrm{P}$ & & 0.034 \\
\hline
\end{tabular}

\section{DISCUSSION}

Prostate cancer is difficult to diagnose at the onset of the disease and, once diagnosed, the cancer has progressed. Epigenetic changes are widespread in patients with prostate cancer and take place at the beginning of the prostate tumor formation (Yegnasubramanian et al., 2004; Berger et al., 2009). It can be used for clinical screening and early detection. DNA methylation occurs in the cytosine of CpG dual nucleotides (Vanaja et al., 2009; Desotelle et al., 2013) and combines methyl groups to the 5th carbon atom of $\mathrm{CpG}$ dual nucleotide cytosine to form 5-methyl cytosine under the catalysis of the DNA methyltransferase (Yegnasubramanian et al., 2008; Khor et al., 2011). CpG dual nucleotides are usually distributed in the $\mathrm{CpG}$ islands in the genome (Kilinc et al., 2012). CpG island methylation is not common in normal cells, while it is widespread in tumor cells (Perry et al., 2006). PITX2, a transcription factor downstream of the canonical Wnt signaling pathway, could regulate the expression of genes involved in cell growth such as CCDN1 and CCDN2. This study analyzed the relationship between PITX2 methylation and prostate cancer prognosis, to determine whether DNA methylation could be used as a prognosis marker for prostate cancer.

Real-time PCR was performed using extracted RNA from benign prostate and tumor tissues. PITX2 expression in prostate cancer tissues was significantly lower than that in benign tissues, while the opposite was observed in term of PITX2 methylation. This suggested that PITX2 methylation was high in tumor tissues and can be used to identify prostate cancer from benign prostatic hyperplasia. Additionally, PITX2 methylation could be used as a prognosis tool based on the PITX2 methylation degree. The $\mathrm{CpG}$ islands in the promoter region of tumor cells are methylated (Schulz and Hatina, 2006; Zheng et al., 2013). DNA methylation might suppress gene expression. Our results indicate that PITX2 was highly methylated and expressed at a low level in cancer tissues. Hypermethylation is the third mechanism in tumor suppressor gene inactivation besides gene silencing and gene mutations, and is the only mechanism in 
some cases (Steiner et al., 2010). Several studies confirmed that PITX2 hypermethylation can cause tumor suppressor gene inactivation and chromosome instability, which leads to abnormal prostatic cell proliferation (Bañez et al., 2010). PITX2 methylation and expression changes have also been found in breast cancer tissue and cell lines (Mirza et al., 2012).

The median value of PITX2 DNA methylation in prostate cancer was $23.3 \%$. The number of patients with low methylation in T2 stage was higher than that in T3 and T4 stages, while the number of patients with high methylation in T2 stage was less than that in T3 and T4 stages. This indicated that a higher DNA methylation degree of PITX2 was associated with higher tumor stage and lower survival rates. $\mathrm{CpG}$ island hypermethylation can inhibit tumor suppressor gene expression, leading to the loss of control of tumor growth. PITX2 can also regulate the androgen receptor and insulin-like growth factor 1 receptor pathways to affect prostate cell growth (Liu et al., 2011). In addition, excessive activation of the Wnt signaling pathway can lead to abnormal cell proliferation and tumor formation. PITX2 might influence tumor development through its participation in the Wnt signaling pathway.

In the subgroup of patients with low methylation a higher number of patients exhibited a survival rate longer than 5 years, while, in the subgroup of patients with high methylation, a higher number of patients exhibited a survival rate shorter than 5 years. This suggested that higher PITX2 methylation levels are associated with worse 5-year survival rate. PITX2 hypermethylation, leading to related gene silencing, plays an essential role in prostate cancer formation. It results in the reduction of PITX2 expression and leads to the worse prognosis (Ummanni et al., 2011). Since patients in the high methylation group exhibited higher tumor stage, higher malignant degree, and more severe disease, they presented the worse prognosis and lower 5-year survival rate. Taken together, our results indicate that PITX2 methylation degree can be used as a predictor for the survival of patients with prostate cancer.

In summary, PITX2 methylation was closely associated with the occurrence and development of prostate cancer. PITX2 expression in prostate tissue was significantly lower than that in benign tissues. The PITX2 gene expression level in prostate cancer was lower than that in benign tissues. A higher DNA methylation degree of PITX2 was associated with higher tumor stages and lower survival rate. PITX2 DNA methylation presents a good predictive value for prostate cancer survival.

\section{Conflicts of interest}

The authors declare no conflict of interest.

\section{ACKNOWLEDGMENTS}

We thank the anonymous reviewers for reviewing this manuscript.

\section{REFERENCES}

Bañez LL, Sun L, van Leenders GJ, Wheeler TM, et al. (2010). Multicenter clinical validation of PITX2 methylation as a prostate specific antigen recurrence predictor in patients with post-radical prostatectomy prostate cancer. J. Urol. 184: 149-156. http://dx.doi.org/10.1016/j.juro.2010.03.012

Berger SL, Kouzarides T, Shiekhattar R and Shilatifard A (2009). An operational definition of epigenetics. Genes Dev. 23: 781-783. http://dx.doi.org/10.1101/gad.1787609 
Bickers B and Aukim-Hastie C (2009). New molecular biomarkers for the prognosis and management of prostate cancer-the post PSA era. Anticancer Res. 29: 3289-3298.

Daniūnaitè K, Berezniakovas A, Jankevičius F, Laurinavičius A, et al. (2011). Frequent methylation of RASSF1 and RARB in urine sediments from patients with early stage prostate cancer. Medicina 47: 147-153.

Desotelle J, Truong M, Ewald J, Weeratunga P, et al. (2013). CpG island hypermethylation frequently silences FILIP1L isoform 2 expression in prostate cancer. J. Urol. 189: 329-335. http://dx.doi.org/10.1016/j.juro.2012.08.188

Goessl C, Müller M, Heicappell R, Krause H, et al. (2001). DNA-based detection of prostate cancer in urine after prostatic massage. Urology 58: 335-338. http://dx.doi.org/10.1016/S0090-4295(01)01268-7

Hermanek P (1992). 1992 tumor classification/developments. Langenbecks Arch. Chir. Suppl. Kongressbd. 40-45.

Hoque MO, Begum S, Topaloglu O, Jeronimo C, et al. (2004). Quantitative detection of promoter hypermethylation of multiple genes in the tumor, urine, and serum DNA of patients with renal cancer. Cancer Res. 64: 5511-5517. http:// dx.doi.org/10.1158/0008-5472.CAN-04-0799

Khor TO, Huang Y, Wu TY, Shu L, et al. (2011). Pharmacodynamics of curcumin as DNA hypomethylation agent in restoring the expression of Nrf2 via promoter CpGs demethylation. Biochem. Pharmacol. 82: 1073-1078. http:// dx.doi.org/10.1016/j.bcp.2011.07.065

Kilinc D, Ozdemir O, Ozdemir S, Korgali E, et al. (2012). Alterations in promoter methylation status of tumor suppressor HIC1, SFRP2, and DAPK1 genes in prostate carcinomas. DNA Cell Biol. 31: 826-832. http://dx.doi.org/10.1089/ dna.2011.1431

Liu L, Kron KJ, Pethe VV, Demetrashvili N, et al. (2011). Association of tissue promoter methylation levels of APC, TGFß2, HOXD3 and RASSF1A with prostate cancer progression. Int. J. Cancer 129: 2454-2462. http://dx.doi. org/10.1002/ijc.25908

Mirza S, Sharma G, Parshad R, Srivastava A, et al. (2012). Clinical significance of promoter hypermethylation of ER $\beta$ and RAR $\beta 2$ in tumor and serum DNA in Indian breast cancer patients. Ann. Surg. Oncol. 19: 3107-3115. http://dx.doi. org/10.1245/s10434-012-2323-5

Perry AS, Foley R, Woodson K and Lawler M (2006). The emerging roles of DNA methylation in the clinical management of prostate cancer. Endocr. Relat. Cancer 13: 357-377. http://dx.doi.org/10.1677/erc.1.01184

Schulz WA and Hatina J (2006). Epigenetics of prostate cancer: beyond DNA methylation. J. Cell. Mol. Med. 10: 100-125. http://dx.doi.org/10.1111/j.1582-4934.2006.tb00293.x

Steiner I, Jung K, Schatz P, Horns T, et al. (2010). Gene promoter methylation and its potential relevance in early prostate cancer diagnosis. Pathobiology 77: 260-266. http://dx.doi.org/10.1159/000318017

Tang D, Kryvenko ON, Mitrache N, Do KC, et al. (2013). Methylation of the RARB gene increases prostate cancer risk in black Americans. J. Urol. 190: 317-324. http://dx.doi.org/10.1016/j.juro.2013.01.083

Tian J, Lee SO, Liang L, Luo J, et al. (2012). Targeting the unique methylation pattern of androgen receptor (AR) promoter in prostate stem/progenitor cells with 5-aza-2'-deoxycytidine (5-AZA) leads to suppressed prostate tumorigenesis. $J$. Biol. Chem. 287: 39954-39966. http://dx.doi.org/10.1074/jbc.M112.395574

Ummanni R, Jost E, Braig M, Lohmann F, et al. (2011). Ubiquitin carboxyl-terminal hydrolase 1 (UCHL1) is a potential tumour suppressor in prostate cancer and is frequently silenced by promoter methylation. Mol. Cancer 10: 129. http:// dx.doi.org/10.1186/1476-4598-10-129

Vanaja DK, Ehrich M, Van den Boom D, Cheville JC, et al. (2009). Hypermethylation of genes for diagnosis and risk stratification of prostate cancer. Cancer Invest. 27: 549-560. http://dx.doi.org/10.1080/07357900802620794

Yegnasubramanian S, Kowalski J, Gonzalgo ML, Zahurak M, et al. (2004). Hypermethylation of CpG islands in primary and metastatic human prostate cancer. Cancer Res. 64: 1975-1986. http://dx.doi.org/10.1158/0008-5472.CAN-03-3972

Yegnasubramanian S, Haffner MC, Zhang Y, Gurel B, et al. (2008). DNA hypomethylation arises later in prostate cancer progression than $\mathrm{CpG}$ island hypermethylation and contributes to metastatic tumor heterogeneity. Cancer Res. 68: 8954-8967. http://dx.doi.org/10.1158/0008-5472.CAN-07-6088

Zheng J, Wang J, Sun X, Hao M, et al. (2013). HIC1 modulates prostate cancer progression by epigenetic modification. Clin. Cancer Res. 19: 1400-1410. http://dx.doi.org/10.1158/1078-0432.CCR-12-2888 